\section{References}

AZUONYE, I. O. (1997) Educational supervision sessions between consultants and trainees. Psychiatric Bulletin, 21, 154-155.

COTTRELL, D. (1999) Supervision. Advances in Psychiatric Treatment, $\mathbf{5}$ 83-88.
HERRIOT, P., BHUI, K. \& LELLIOT, P. (1994) Supervision of trainees.

ROBERTSON, J. R. \& DEAN, A. (1997) General professional training: consultant supervision of trainees. Advances in Psychiatric Treatment, 3 347-351.

Psychiatric Bulletin, 18, 474-476
*Sati Sembhi Mental Health LiaisonTeam, Waterlow Unit, Highgate Hill, London N19 5NX, Gill Livingston Royal Free and University College Medical School, Department of Psychiatry and Behavioural Sciences, Wolfson Building, 48 Riding House Street, London W1N 8AA
ROYAL COLLEGE OF PSYCHIATRISTS (1998) Higher Specialist Training Handbook. Occasional Paper OP 43. London: Royal College of Psychiatrists.

original papers

MARK DAVIES

\title{
Towards the development of a reciprocal liaison service
}

\author{
A survey of attitudes
}

\section{AIMS AND METHOD}

The aim of this survey was to determine attitudes among consultants in different specialities towards the development of a reciprocal liaison service providing access for psychiatric patients to medical and surgical liaison services equal to the access of medical and surgical patients to psychiatric liaison services. All medical, surgical and psychiatric consultants in a district health service were surveyed, with a total response rate of $48 \%$.

\section{RESULTS}

The mean number of medical and surgical patients requiring a psychiatric liaison service was $6 \%$. The mean number of psychiatric patients requiring medical and surgical liaison services was $11 \%$. Ratings overall for various components of the two types of liaison service were generally similar, with acute assessments and follow-up being given a high priority for both types.

\section{CLINICAL IMPLICATIONS}

As liaison services are developed, the notion of equity of access for all patients is paramount. Commissioning of such services should thereby specify the reciprocal nature of development. This survey shows that generally there is a positive attitude to the development of such a service.
Psychiatric liaison services for medical and surgical patients are a well-established, although often underresourced and underdeveloped, feature of most local health services. Studies consistently show that this type of service reduces hospital stays and, ultimately, costs (Smith et al, 1995; Hall \& Frankel, 1996). However, a clearly defined reciprocal service provided by medical and surgical services for psychiatric patients is poorly researched and developed. Cooperative intervention between physical and mental health services can improve detection and management of 'cross-speciality' disease (Saravay, 1996). Comorbidity of mental and physical health problems can be complex, requiring close working between mental and physical health professionals (Buckley et al, 1995; Rustomjee \& Smith, 1996). Confronting stigma towards people with mental illness has taken on a higher profile recently with the launch of the Royal College of Psychiatrists anti-stigma campaign (Cowan \& Hart, 1998). Part of the process of destigmatising mental illness is to increase the access of psychiatric patients to appropriate medical and surgical care. People with mental illnesses are often perceived as requiring less physical health care than the non-mentally ill (Dolinar, 1993). Communication of physical symptoms may be hampered by poor communication skills, and understanding of physical disease impaired. Mental health units are often sited away from medical and surgical units, leading to marginalisation of psychiatric patients and staff. This can lead to inequitable access of mental health patients to physical health services. One way to overcome this inequity would be to integrate medical and surgical liaison services for mental health patients with developments in psychiatric liaison services for medical and surgical patients. To determine whether such an integration would be feasible, a survey was undertaken of medical, surgical and psychiatric consultants asking about their attitudes to the development of a reciprocal liaison service.

\section{The study}

All medical and surgical consultants were identified in a large district general hospital serving a town on the south coast of England with a population of 160000 people. Additionally, all consultants in the local mental health service covering a large proportion of the same population were identified. Those identified were then sent a questionnaire. Each respondent was first asked to signify the speciality in which they worked, along with an estimate of how many of their patients might require a liaison service.

Respondents were then asked to complete two sections, the first containing components of a psychiatric liaison service for medical and surgical patients and the second section, components of a physical health liaison service for mental health patients. Respondents were 
asked to rate the components on a five-point scale ranging from necessary (four) to unimportant (zero). It was emphasised that respondents should complete both sections. For each of the two types of liaison service, the number of respondents indicating each of the possible ratings (i.e. 4--0) for a component was calculated. Each of these totals was then multiplied by the corresponding rating. An average was then calculated from the resultant values to give an overall 'priority value' for each component. The priority value was intended to indicate the overall relative preference of respondents for each component of the two liaison services. The higher the priority value, the higher that component was rated by each group as a whole. The priority values allocated by medical and surgical consultants were combined to give average values for 'physical health services'.

\section{Findings}

Of the consultants contacted, 30 were surgical, 36 medical and 20 psychiatric. Of these, surgical consultants returned $12(40 \%)$ questionnaires, medical consultants 19 (53\%) and psychiatric consultants 10 (50\%). For the question on the percentage of their own patients requiring psychiatric liaison services, surgical consultants quoted a mean of $2 \%$ (range 1--5\%), two not indicating a figure. Medical consultants specified a mean of $10 \%$ (range 1-33\%), with five not indicating a figure. For psychiatric patients requiring medical or surgical liaison,

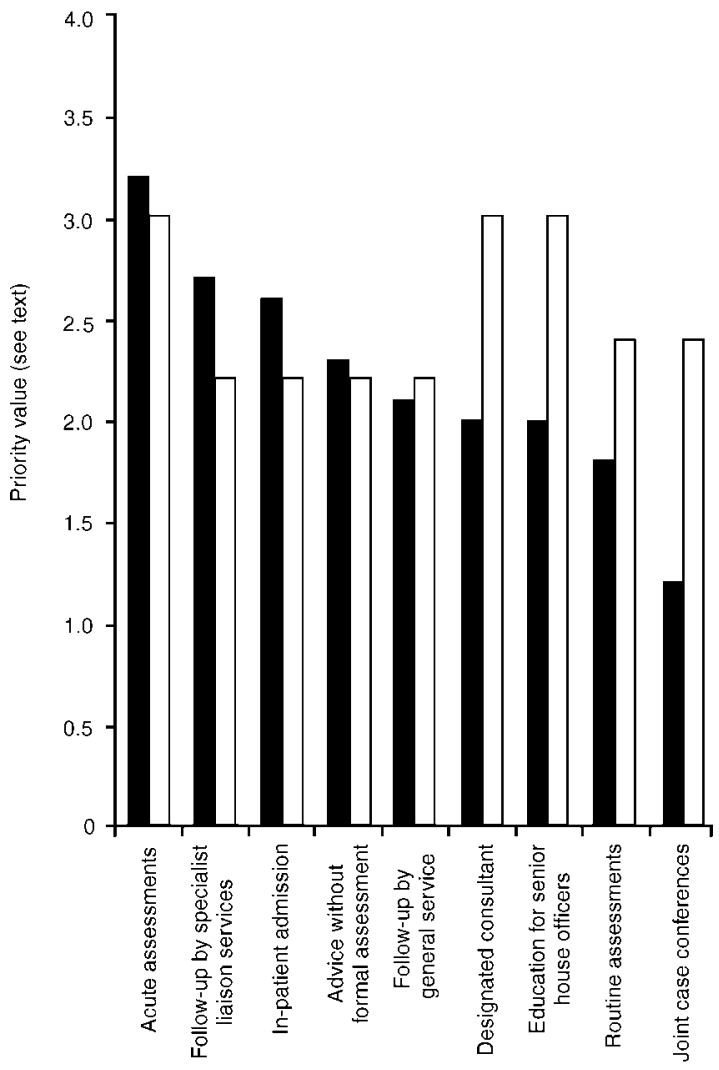

Fig. 1. Priority values given by all respondents for a psychiatric liaison service for medical/surgical patients. $\square$, medical and surgical consultants $(n=31) ; \square$, psychiatric consultants $(n=10)$.

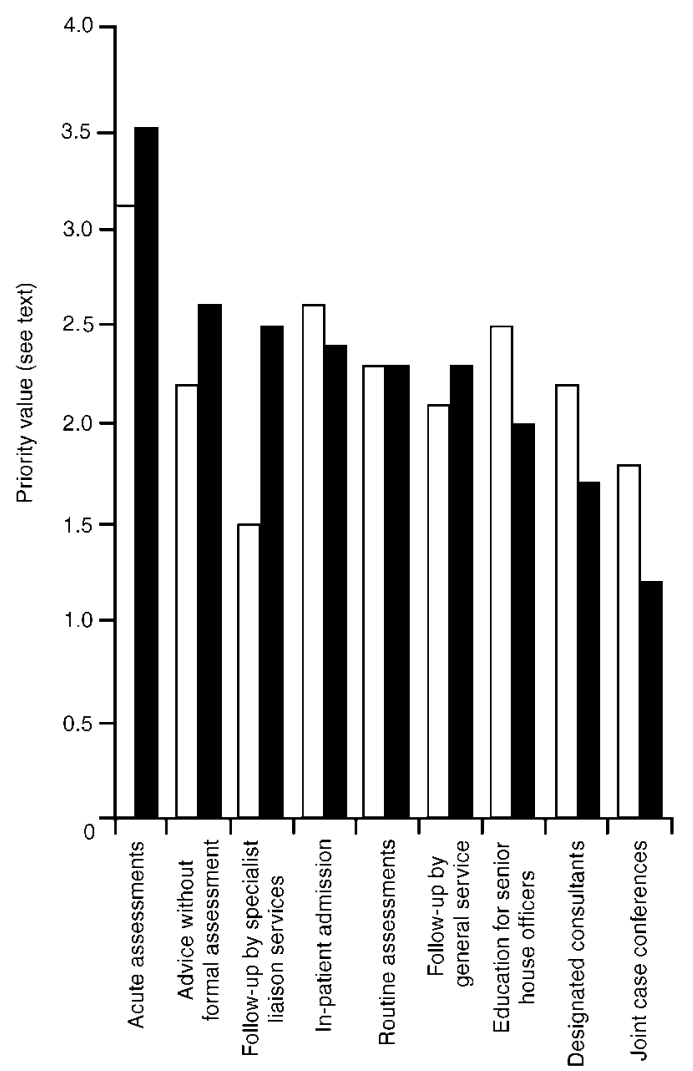

Fig. 2. Priority values given by all respondents for a medical/surgical liaison service for psychiatric patients. $\square$, psychiatric consultants $(n=10)$; medical and surgical consultants $(n=31)$.

psychiatric consultants quoted a mean of $11 \%$ (range 5 $25 \%$ ), two not giving a score for this item. The priority values for each of the liaison services by both the medical and surgical consultants and the psychiatric consultants are presented in Figs $1 \& 2$.

Overall, the pattern of relative scoring is similar for the two groups of consultants for both types of liaison service. For psychiatric liaison services for medical and surgical patients, medical and surgical consultants considered acute assessments the most important, with follow-up by a specialist liaison service the next most important item. Joint case conferences and routine assessments were considered least important. Psychiatric consultants felt acute assessments, a designated liaison consultant, and education for senior house officers (SHOs) were most valuable, with follow-up by general services or a specialist liaison service being two of the least valuable components. Medical and surgical consultants regarded $\mathrm{SHO}$ education and a designated consultant as less important.

For medical and surgical liaison services for psychiatric patients, psychiatric consultants thought acute assessments followed by in-patient admission were the most important, with follow up by a specialist liaison service the least important. Surgical and medical consultants agreed that acute assessments were the most important, followed by advice without formal assessment. A designated liaison consultant and joint case conferences were given lower ratings by these consultants. 


\section{Comment}

This survey gives an indication of the attitudes of consultants in both mental and physical health services to the potential development of a reciprocal liaison service. The study was undertaken on a relatively small number of consultants in a single district service. The average return rate of $48 \%$, with only $40 \%$ of consultant surgeons responding, meant information on the views of a majority of consultants was not forthcoming. The relatively low returns may be explained by the poorly developed area of reciprocal liaison, along with the prospect of increased workloads for both physical and mental health services. Future studies in this area may require larger study populations, with a study design to improve the proportion of respondents.

The average range of $6 \%$ of medical and surgical patients requiring a psychiatric liaison service is just over half the $11 \%$ of psychiatric patients requiring a physical health liaison service. The prioritisation of components show similar profiles for physical and mental health consultants, with some important differences. The low rating by medical and surgical consultants for $\mathrm{SHO}$ education regarding psychiatric problems in medical and surgical patients is of concern in the light of studies demonstrating significant levels of mental illness missed by medical and surgical services (Clarke et al, 1995). Medical and surgical consultants themselves may be keen to improve their knowledge of psychiatric disorders and their management (Creed, 1992).

With evidence that liaison services can reduce hospital stays, and therefore costs, a reciprocal liaison service is conceivably an economically as well as clinically desirable area for development. The results of this survey support the viability of such a service. Further, the development of reciprocal liaison services with improved physical health services for psychiatric patients will be another step closer to the destigmatisation of people with mental illness.

\section{References}

BUCKLEY, P. F., FREYNE, A. \& WALSHE, N. (1995) The medical-psychiatry unit: A pilot study of conjoint care within an Irish general hospital. Psychosomatics, 35, 515-519.

CLARKE, D. M., McKENZIE, D. P. \& SMITH, G. C. (1995) The recognition of depression in patients referred to a consultation-liaison service, Journal of Psychosomatic Research, 39, 327-334.

COWAN, L. \& HART, D. (1998) Changing minds: every family in the land. Psychiatric Bulletin, 22, 593-594.

CREED, F. (1992) The future of liaison psychiatry in the UK. International Review of Psychiatry, 4, 99-107.

DOLINAR, L. J. (1993) Obstacles to the care of patients with medical-psychiatric illness on general hospital psychiatry units. General Hospital Psychiatry, 15, 14-20.
HALL, R. C.W. \& FRANKEL, B. L. (1996) The value of consultation-liaison interventions to the general hospital. Psychiatric Services, 47, 418-420. RUSTOMJEE, S. \& SMITH, G. C. (1996) Consultation-liaison psychiatry to renal medicine: work with an in-patient unit. Australian \& New Zealand Journal of Psychiatry, 30, 229-237.

SARAVAY, S. M. (1996) Psychiatric interventions in the medically ill: outcome and effectiveness research. Psychiatric Clinics of North America, 19, 467-480

SMITH, G. R., ROST, K. \& KASHNER, T. M. (1995) A trial of the effect of a standardised psychiatric consultation on health outcomes and costs in somatising patients, Archives of General Psychiatry, 52, 238-243.

Mark Davies Consultant Psychiatrist, Community Mental HealthTeam, Waterford House, 142 Station Road, New Milton, Hampshire BH25 6LP

P. WHEWELL AND D. BONANNO

\title{
The Care Programme Approach and risk assessment of borderline personality disorder
}

\author{
Clinical validation of the CORE risk sub-scale
}

\section{AIMS AND METHODS}

This paper describes the validation of self-report of risk by patients with borderline personality disorder (BPD) as compared with the judgement of experienced psychotherapists in regular contact with them. The aim was to validate the Clinical Outcomes in Routine Evaluation System (CORE) self-report in order to be able to use it to monitor risk change for patients with BPD in psychotherapy and general psychiatric settings.

\section{RESULTS}

There was significant separation correlation between CORE risk subscales for self-harm, suicide and risk to others and therapists' estimation of significant risk $v$. no significant risk.

\author{
CLINICAL IMPLICATIONS \\ Using the cut-offs described, we \\ suggest that the CORE questionnaire \\ risk sub-scales can be used to assess \\ significant risk for patients with BPD \\ in psychotherapy, and in psychiatric \\ and community health teams. The \\ sub-scales should also prove valuable \\ in allocating Care Programme \\ Approach status.
}

There has been increasing concern about patients with personality disorders in terms of risk to others and risk to themselves, as reflected in a number of official inquiries. Recently there has been an inquiry that hinged upon the lack of clarity in psychiatric risk assessment of borderline personality disorder (BPD) (Brown et al, 1999). It is well known that patients with BPD pose difficulties with regard to clinical management and we are aware of much 